\title{
ENSAYO
}

\section{El uso fraudulento del contrato sindical en Colombia y sus implicaciones en la equidad salarial}

The fraudulent use of the union contract in Colombia and its implications in salary equity

Sergio Andrés Giraldo Galeano ${ }^{1}$

Tipo de artículo: Ensayo. Recibido: 11 de octubre de 2019. Aprobado: 13 de noviembre de 2019.

La desregulación y flexibilización del trabajo introducen como normalidad lo que durante largo tiempo fue una catástrofe superable: la economía informal y el sector informal.

Ulrich Beck

Resumen: Este ensayo plantea un análisis crítico del contrato sindical en Colombia, como institución jurídica definida en el Código Sustantivo de Trabajo, a la cual se le ha dado un uso fraudulento, especialmente a partir de los decretos 1429 de 2010 y 36 de 2016. Esta situación ha favorecido la acumulación de capital en detrimento de las libertades sindicales y de los derechos históricamente reivindicados por los trabajadores colombianos. En este sentido, el contrato sindical se ha convertido en una figura que distorsiona el significado histórico del derecho de asociación sindical, propicia la intermediación laboral y precariza los derechos individuales y colectivos de los trabajadores colombianos. Finalmente, se presenta una breve reflexión acerca de la manera en que el contrato sindical facilita la elusión del principio de equidad retributiva y afecta el sentido del ingreso salarial como principal indicador del empleo de calidad.

Palabras clave: Contrato sindical, flexibilización laboral, precariedad, igualdad salarial, principios del derecho laboral.

Abstract: This essay raises a critical analysis of the union contract in Colombia, as a legal institution defined in the Substantive Labor Code, which has been fraudulently used, especially from the decrees 1429 of 2010 and 36 of 2016. This situation has favored the accumulation of capital to the detriment of trade union freedoms and rights historically claimed by Colombian workers. In this sense, the union contract has become a figure that distorts the historical meaning of the right to promote labor intermediation and precarious the individual and collective rights of Colombian workers. Finally, a brief reflection is presented on how the union contract facilitates the avoidance of the principle of remunerative equity, affecting the sense of wage income as the main indicator of quality employment.

Keywords: Union contract, labor flexibility, job insecurity, salary equity, labor law principles

Cómo citar este artículo: Giraldo Galeano, S. A. (2020). El uso fraudulento del contrato sindical en Colombia y sus implicaciones en la equidad salarial. Memorias Forenses, (3), 59-65.

1 Docente e investigador del Tecnológico de Antioquia. Abogado laboralista y magíster en Derecho de la Universidad de Antioquia. Correo electrónico: sergio.giraldo@tdea.edu.co 


\section{¿Qué es el contrato sindical?}

El contrato sindical es una de las tres formas de contratación colectiva que existen en Colombia, junto con la convención colectiva de trabajo, que se celebra entre un empleador, o un grupo de empleadores, con trabajadores sindicalizados, y el pacto colectivo, que opera entre un empleador o un grupo de empleadores con trabajadores no sindicalizados. Su fundamento legal se haya consagrado en los artículos 482, 483 y 484 del Código Sustantivo del Trabajo y se define como "un acuerdo que celebran uno o varios sindicatos de trabajadores con uno o varios empleadores o sindicatos patronales para la prestación de servicios o la ejecución de una obra por medio de sus afiliados".

El contrato sindical nace como respuesta a una situación muy particular en la que algunos sindicatos gremiales, sobre todo de transporte fluvial en el río Magdalena, suscribían acuerdos con las empresas navieras en la década de los treinta del siglo pasado, básicamente para cumplir con la labor de carga y descarga de mercancías o insumos. Para regular este tipo de convenios, se creó esta institución con el Decreto 2350 de 1944 y la Ley 6 de 1945, que más tarde serían reguladas por el Capítulo III del Título III del Código Sustantivo del Trabajo (CST) y por el Decreto 1469 de 1978. Recientemente, y a partir de la segunda década del siglo XXI, la figura sufriría una significativa reconfiguración normativa a partir de los decretos 1429 de 2010 y 36 de 2016. Es de anotar que, desde la entrada en vigencia de estos dos decretos, el contrato sindical se convirtió en la forma de contratación colectiva preferida por los empleadores.

El remozado interés del Gobierno nacional en esta institución se presenta porque, según sus defensores, el objetivo del contrato sindical es que los sindicatos puedan participar en la gestión de las empresas, en la promoción del trabajo colectivo y en la generación de empleo (ENS, 2017). De esta manera, se intenta impulsar a través del contrato sindical una forma de "sindicalismo participativo", que cree en la posibilidad de construir alianzas estratégicas entre patronos y obreros, y que intenta superar y dejar atrás el tradicional "sindicalismo clasista", fundado en los principios de: (i) lucha por los intereses de la clase obrera; (ii) unidad sindical; (iii) la democracia interna en el funcionamiento del sindicato, y (iv) independencia política.

Ahora bien, a pesar de que esta institución jurídica laboral existe, como ya se dijo, desde antes de la expedición del Código Sustantivo del Trabajo (1950), su uso fue circunstancial o eventual en Colombia hasta el año 2010. Pero a partir del Decreto 1429 del mismo año que, ante el auge de la tercerización ilegal, prohibió el envío de personal misional por parte de las cooperativas de trabajo asociado, el uso de los contratos sindicales creció de manera exponencial. Así, entre 2006 y 2010, tan solo 170 contratos sindicales fueron registrados en el Ministerio de Trabajo, pero entre los años 2011 y 2015 se suscribieron un total de 5.877, presentándose un incremento del $3.357 \%$ en la celebración de contratos sindicales en el mismo período.

Debemos añadir que, en la Sentencia T-457 de 2011 , la Corte Constitucional consideró que no puede existir una vinculación laboral entre los afiliados a un sindicato y la organización sindical misma, pues se desdibujaría completamente el sindicalismo tal como es pensado en la Constitución colombiana, en cuanto no puede existir una relación de subordinación entre el sindicato y los afiliados partícipes. Por eso el contrato sindical permite conformar sindicatos, incluso con personas que carecen de la más mínima afinidad político-ideológica - lo que atenta contra los presupuestos fundacionales de la organizaciónpara que presten sus servicios o ejecuten una obra, no ya como personas naturales, sino cubiertos por la persona jurídica del sindicato.

Así, se observa en el contrato sindical una novedosa forma de hacer intermediación laboral ilegal, en la cual el tercero, sindicato, triangula la relación laboral y suministra personal a empresas o entidades usuarias, las cuales se benefician de la mano de obra necesaria para ejecutar sus actividades productivas, librándose así de las responsabilidades patronales. 


\section{El contrato sindical como instrumento de precarización e intermediación laboral}

Desde esta perspectiva, se presenta una instrumentalización fraudulenta del contrato sindical, primero, como figura mixtificadora del espíritu sindical y, segundo, como medio para la concreción de muchas de las expectativas neoliberales en materia laboral como lo son la contratación flexible para facilitar la movilidad del personal, la exclusión de responsabilidades patronales, el ahorro en los gastos de prestaciones sociales y de seguridad social de los trabajadores, el entorpecimiento de los procedimientos de reivindicación obrera y, muy especialmente, la ineficacia sindical por la distorsión que se hace de su finalidad.

Para los empresarios y jefes de empresa la instrumentalización del contrato sindical resulta bastante halagüeña en la generación de ganancias, pues, hacer uso de esa figura jurídica como mecanismo de exclusión de responsabilidad patronal les representa un ahorro económico cuantificable, obviamente en detrimento de garantías laborales individuales y colectivas de sus trabajadores.

\section{Afectación de derechos laborales individuales.}

Las condiciones laborales de cada trabajador vinculado por medio de contrato sindical se encuentran descritas en el contrato celebrado entre la empresa y el sindicato, y en él se especifica, principalmente, el objeto del mismo, la cantidad de personal requerido, los horarios, los salarios, las prestaciones, la seguridad social, los auxilios y las bonificaciones.

Sin embargo, la remuneración percibida por cualquier trabajador, es decir, el salario, en el marco del contrato sindical, pasa a denominarse compensación ordinaria. Así las cosas, el trabajador recibe una compensación económica periódica por su trabajo, como una búsqueda de equiparación de la prestación realizada por el empleador. Esta lógica es más propia de las dinámicas privadas y mercantiles que de las relaciones laborales, puesto que la bilateralidad y la correlatividad de las obligaciones son principios que caracterizan la celebración, interpretación y aplicación de los negocios jurídicos privados.

El concepto de salario, en el derecho laboral, nada tiene que ver con una cuantificación del trabajo compensado con una cuantía económica, pues el trabajo no es un aporte que se haga a un determinado beneficiario, sino la actividad que dignifica a la persona, construye su identidad, se inserta en la comunidad, configura un proyecto de vida para sí y su familia, encaminado al ascenso social (Bedoya, 2003).

Por otra parte, el contrato sindical afecta negativamente muchos otros derechos laborales individuales. Como ya vimos, lo que para la ley y la doctrina es prima legal, para el contrato sindical pasa a ser compensación semestral; pero también las cesantías se consideran compensación anual y los intereses a las cesantías son denominados compensación extraordinaria. El extremo radica en que los trabajadores pasan a llamarse "afiliados partícipes", para esquivar las obligaciones laborales e impedir que los trabajadores "sindicalizados" promuevan, entre otros asuntos, la convocatoria a asamblea general o la conformación de la junta directiva. Estos malabares lingüísticos lógicamente son construcciones deliberadas dirigidas a la configuración de nuevas realidades laborales desde un lenguaje flexible para denominar la relación laboral, y con ello tergiversar su naturaleza.

En suma, nos encontramos ante una dialéctica alternativa, íntimamente ligada al proyecto neoliberal de la desregulación laboral. Ante una normatividad sólida, producto de logros históricos en garantía del trabajador, la estrategia consiste en crear condiciones que, en apariencia, no encuentran identidad con las reglas laborales existentes para, de esta manera, evitar su eficacia (Supiot, 2008).

Valga aclarar que no solo las prestaciones sociales de los afiliados partícipes están a cargo del sindicato, dado que este debe, además, hacer los descuentos y consignaciones por concepto de seguridad social, desarrollar programas de prevención de riesgos y capacitación de los trabajadores en la materia, seleccionar los trabajadores, hacer los procesos disciplinarios internos, entre muchas 
otras obligaciones que, desde el principio de la prevalencia de la realidad sobre las formas, lo configuran jurídicamente como empleador.

Finalmente, otra garantía fundamental, agravada por la instrumentalización fraudulenta del contrato sindical, es la estabilidad laboral, ya que el afiliado partícipe está condicionado por los términos que previamente se hicieron en el contrato sindical. Sobre este aspecto, se ha encontrado que la duración de los contratos sindicales no suele exceder un año, momento en el que todo el personal se desvincula de la empresa y queda desempleado, hasta la celebración de un nuevo contrato sindical, cuyas condiciones volverán a depender del arbitrio de la empresa beneficiaria y el sindicato contratista.

\section{Afectación de derechos laborales colectivos.}

La libertad sindical, en su dimensión asociativa consagrada en el Artículo 39 de la Constitución Política, se afecta gravemente con el uso fraudulento del contrato sindical puesto que, para acceder a un empleo por este medio, el trabajador debe afiliarse obligatoriamente a la organización, vulnerando con ello la libertad negativa de afiliación que consiste en estar exento de presión para decidir si se asocia o no a un sindicato. Recordemos que la esencia de la sindicalización es la convicción política e ideológica que tiene el afiliado para alcanzar mejores condiciones laborales, sin embargo, la realidad arroja que los afiliados que trabajan con contrato sindical están sindicalizados por la necesidad de trabajar, más que por una finalidad política reivindicatoria. En definitiva, se usa la necesidad del trabajador para convertir el sindicato en una agencia de empleo, y no en lo que su sentido ontológico dicta: una organización social pilar de una democracia fundamentada en el diálogo social. Precisamente la existencia de este tipo de falsos sindicatos desestimula el sindicalismo real, al cooptar a los trabajadores e impedir que ejerzan verdaderas actividades reivindicativas. Se dice que el número de trabajadores asociados en Colombia crece, pero en realidad cada vez son menos los trabajadores organizados a fin de defender sus intereses y los de sus familias.
La negociación colectiva y los mecanismos de presión del sindicato lejos están de concretarse para los afiliados partícipes, no existe una estructura diseñada para estos fines; los sindicatos creados para celebrar contratos sindicales, en la práctica, no presentan pliegos de peticiones ni planean estrategias a favor de sus afiliados, no tienen como finalidad reivindicar beneficios para sus afiliados y tampoco usan los mecanismos legítimos de la histórica lucha obrera.

Estos sindicatos de papel se dedican a administrar los contratos y las obligaciones que se desprenden del contrato sindical, y la formación política dentro del sindicato se reduce a un lánguido adoctrinamiento a favor del "nuevo sindicalismo". La figura del contrato sindical alimenta un sindicalismo pasivo, siempre a merced de las determinaciones a las que lleguen sus representantes con la empresa beneficiaria, respecto a las condiciones laborales de sus afiliados partícipes.

\section{El contrato sindical vulnera el principio de equidad retributiva}

El nuevo paradigma laboral que se viene instalando en el país, como consecuencia de la implementación de figuras que, como el contrato sindical, facilitan el fraude al contrato individual de trabajo y con ello a la posibilidad de acceder a la contratación colectiva, nos pone frente a situaciones que otrora resultarían paradójicas y absurdas. Los nuevos paradigmas laborales ahondan la crisis de identidad que atraviesa el proletariado mundial y nacional, que ya no se identifica con la clase social trabajadora y que no se erige como el sujeto histórico capaz de liderar transformaciones sociales de gran calado.

El contrato sindical, a mediano y largo plazo, propicia una transformación de las condiciones fácticas que configuran la identidad proletaria puesto que los trabajadores enganchados mediante esta figura no tienen empleos estables y su permanencia depende de la vigencia del contrato entre la empresa y el sindicato contratante, que generalmente son periodos de un año o mientras dure la obra o labor para desempeñar, su salario difiere de lo que 
obtienen por el mismo trabajo personas contratadas directamente por las empresas, y no participan de las convenciones o pactos de los trabajadores vinculados.

La precarización laboral es, en gran medida, un paso necesario en la consolidación del proyecto neoliberal, y esto no porque afecte negativamente los ingresos y las condiciones laborales de los trabajadores, sino porque produce el desarraigo del lugar donde estos despliegan su actividad productiva, en el entendido que, en una relación signada por la precariedad, no es posible construir vínculos afectivos y solidarios con las personas con las que se comparte el ciclo productivo. La actividad laboral se vuelve superficial para el obrero, un simple medio para solventar la existencia y no el camino para alcanzar la justicia social.

Ante esta afirmación, y teniendo en cuenta que el salario es el principal indicador de un empleo de calidad, es posible vislumbrar una vulneración al principio de equidad retributiva, mediante el cual se pretende evitar el tratamiento desigual en las relaciones laborales, acudiendo al pago de salarios diferenciados sin ninguna razón objetiva o justificable.

Para la Sala Laboral de la Corte Suprema de Justicia, el principio de equidad retributiva tiene dos acepciones: la primera de ellas busca enfrentar las discriminaciones directas o tratos salariales diferentes fundados en motivos ilegítimos a través del principio "a trabajo igual, salario igual", en otras palabras, la premisa se traduce en que cuando dos trabajadores realicen la misma labor deben recibir igual retribución. La segunda acepción del principio de equidad retributiva busca enfrentar las discriminaciones tanto directas como indirectas, entendidas éstas como tratos diferenciados que entrañan alguna segregación indebida. En otras palabras, la Corte señala que esta última acepción del principio podría expresarse de otra manera: si dos trabajadores realizan trabajos que agregan el mismo valor - bien sea por desempeñar el mismo trabajo, bien sea por desempeñar oficios diferentes pero que aportan el mismo valor-, deben recibir igual retribución.
De las dos acepciones descritas se deduce que, en términos salariales, el principio de equidad retributiva propende por un tratamiento igualitario entre los trabajadores que realizan la misma labor para la misma empresa o persona y entre quienes, a pesar de desempeñarse en oficios diferentes, aportan el mismo valor en beneficio del tercero contratante o beneficiado.

Desde el derecho internacional, el principio de equidad retributiva se encuentra contemplado en la Declaración Universal de los Derechos Humanos (1948), específicamente en el artículo 23 numeral segundo, que de manera textual establece: "Toda persona tiene derecho, sin discriminación alguna, a igual salario por trabajo igual".

En Colombia, la Ley 6 de 1945, en su artículo 5, hizo referencia a este principio al proscribir pagar salarios diferentes ante trabajos equivalentes. Posteriormente, el Código Sustantivo del Trabajo en su artículo 143 adoptó el principio de "a trabajo igual salario igual", artículo que fue modificado por el artículo 7 de la Ley 1496 de 2011 que introduce el concepto "a trabajo de igual valor salario igual". De manera textual, establece el Código Sustantivo:

ARTÍCULO 143. A TRABAJO DE IGUAL VALOR, SALARIO IGUAL. <Artículo modificado por el artículo 7 de la Ley 1496 de 2011>:

1. A trabajo igual desempeñado en puesto, jornada y condiciones de eficiencia también iguales, debe corresponder salario igual, comprendiendo en este todos los elementos a que se refiere el artículo 127.

2. No pueden establecerse diferencias en el salario por razones de edad, género, sexo nacionalidad, raza, religión, opinión política o actividades sindicales.

3. Todo trato diferenciado en materia salarial o de remuneración, se presumirá injustificado hasta tanto el empleador demuestre factores objetivos de diferenciación.

De lo establecido en este artículo, y atendiendo a lo señalado por la Sala Laboral de la Corte Suprema de Justicia, es posible considerar que dos trabajos 
se consideran iguales cuando "son iguales el puesto, la jornada y las condiciones de eficiencia de quienes lo desempeñan". En el caso concreto, es posible advertir que los trabajadores vinculados laboralmente a través del contrato sindical desempeñan funciones similares en condiciones y puestos de trabajo idénticos, lo que implica que, atendiendo al principio de equidad retributiva, deban recibir igual remuneración por el servicio personal prestado, esto es, un salario y no una compensación ordinaria.

Para la Sala Laboral de la Corte el artículo 143 del Código Sustantivo de Trabajo contempla tres criterios que deben cumplirse para que dos trabajadores se consideren iguales y reciban la misma retribución: dos de tipo objetivo (puesto y jornada) y uno subjetivo (condiciones de eficiencia). Señala la Corte que, si uno solo de esos elementos es distinto, justificará una diferencia retributiva entre ambos trabajadores, pues, en tal hipótesis, sus trabajos no se considerarán iguales.

Sin embargo, en ninguno de ellos se enuncia la modalidad contractual como criterio diferenciador entre dos personas que realizan la misma actividad para un tercero. Por tanto, no es de recibo que la modalidad contractual sea un elemento diferenciador del salario, más aún cuando no parece ser esta una causal válida u objetiva que justifique tal diferenciación. En ello radica, evidentemente, la perversidad del contrato sindical.

\section{Palabras finales}

La Sentencia T-418 de 1992, cuyos magistrados ponentes fueron Ciro Angarita y Jaime Sanín Greiffenstein, considerada un hito en el desarrollo jurisprudencial del Derecho del Trabajo, estableció que la libertad sindical es un derecho fundamental expresamente reconocido en el capítulo I del título || de la Carta Política de Colombia. Además, fue clara al señalar que este derecho no se puede seguir viendo como un simple derecho secundario, sino como un elemento indispensable del Estado, la sociedad y los trabajadores y componente esencial de la democracia.

En este sentido, este ensayo pretende servir como guía para analizar críticamente los elementos más controversiales del contrato sindical en Colombia y evidenciar el uso fraudulento que se le ha dado convenientemente a la figura para atacar las libertades sindicales y debilitar así los derechos que, a lo largo de muchos años, lograron conquistar los trabajadores colombianos. El contrato sindical se ha convertido en una figura que distorsiona el significado histórico del derecho de asociación sindical, propicia la intermediación laboral y precariza los derechos individuales y colectivos de los trabajadores colombianos, facilitando, además, la elusión del principio de equidad retributiva y el sentido del ingreso salarial como principal indicador del empleo de calidad.

Conflicto de intereses: El autor declara no tener conflictos de intereses. 
Bedoya, M. R. (2003). El derecho al trabajo y el derecho de asociación: tensiones entre el modelo neoliberal globalizado y la Constitución Política de 1991. Medellín: Universidad de Antioquia.

Congreso de la República de Colombia. (14 de marzo de 1945). Ley 6 de 1945. "Por la cual se dictan algunas disposiciones sobre convenciones de trabajo, asociaciones profesionales, conflictos colectivos y jurisdicción especial de trabajo". Diario Oficial, 25790.

Congreso de la República de Colombia (7 de junio de 1951). Código Sustantivo del Trabajo (Con base en la Edición Oficial del Código Sustantivo del Trabajo con sus modificaciones, ordenada por el artículo 46 del Decreto Ley 3743 de 1950, Diario Oficial N ․ำ 27.622, compilando los Decretos 2663 y 3743 de 1950 y 905 de 1951).

Congreso de la República de Colombia. (1991). Constitución Política de Colombia. Bogotá: Imprenta Nacional.

Congreso de la República de Colombia. (29 de diciembre de 2010). Decreto 1429 de 2010. "Por la cual se expide la Ley de Formalización y Generación de Empleo". Diario Oficial, 47.937.

Corte Constitucional de Colombia. (19 de junio de 1992). Sentencia T-418/92B. Magistrados Ponentes: Dr. Jaime Sanín Greiffenstein y Dr. Ciro Angarita Barón.
Corte Constitucional de Colombia. (27 de mayo de 2011). Sentencia T-457/11. Magistrado Ponente: Luis Ernesto Vargas Silva.

Escuela Nacional Sindical (ENS). (2017). El contrato sindical a la luz del trabajo decente. Medellín: ENS.

Presidencia de la República de Colombia. (27 de octubre de 1944). Decreto Ley 2350 de 1944. "Por el cual se dictan lagunas disposiciones sobre Convenciones de Trabajo, asociaciones profesionales, conflictos colectivos y jurisdicción especial del trabajo".

Presidencia de la República de Colombia. (19 de julio de 1978). Decreto 1469 de 1978. "Por el cual se reglamentan algunas disposiciones laborales".

Presidencia de la República de Colombia. (12 de enero de 2016). Decreto 36 de 2016. "Por el cual se modifican los artículos 2.2.2.1.16 al 2.2.2.1.23 y se adicionan los artículos 2.2.2.1.24 al 2.2.2.1.32 del Capítulo 1 del Título 2 de la Parte 2 del Libro 2 del Decreto 1072 de 2015, Decreto Único Reglamentario del Sector Trabajo, y se reglamentan los artículos 482, 483 y 484 del Código Sustantivo de Trabajo". Diario Oficial, 49753.

Supiot, A. (2008). El derecho del trabajo. Buenos Aires: Heliasta. 